\title{
SALIBA, Elias Thomé. \\ Raízes do Riso. A representação humorística na história brasileira: da Belle Époque aos primeiros tempos do rádio.
}

Tania Regina de Luca

UNESP/Assis

São Paulo: Companhia das Letras, 2002, 366 pp.

O período denominado de pré-moderno tem sido objeto, especialmente a partir da década de 1980, de profunda reavaliação histórica. A própria terminologia consagrada para nomeá-lo já denuncia o anátema que tem pesado sobre a produção literária das primeiras décadas republicanas, que esteve longe de contar com o entusiasmo de alguns dos nossos principais críticos. A idéia de negatividade acabou por se espraiar para o ambiente intelectual e cultural como um todo e mesmo quando se tenta atribuir ao pré-modernismo um sentido forte, ou seja, de antecipação temática e formal do que estaria por vir, a interpretação ainda permanece atada a parâmetros externos, uma vez que o período é avaliado em função de quanto é capaz de anunciar o futuro, numa assunção implícita de que o mesmo carece de essência e sentido próprios.

O peso simbólico de 1922 é de tal ordem que não apenas se impôs enquanto marco periodizador da cultura brasileira, como também homogeneizou os antecessores sob rótulos genéricos, subtraindo-lhes a identidade. A coerência e o equilíbrio desse quadro, construído em larga medida pelo discurso dos modernistas, cujas opiniões, testemunhos e análises foram incorporados de forma pouco crítica pela historiografia, vêm sendo perturbados em mais de um sentido.

O trabalho de Elias Thomé Saliba constitui-se numa significativa contribuição para o premente esforço de releitura das décadas iniciais do século XX. $\mathrm{O}$ autor propõe-se a estudar a representação humorística brasileira durante a Belle Époque e nos primeiros tempos do rádio e, para tanto, apresenta os resultados da sua pesquisa em quatro capítulos, precedidos por um prólogo.

No texto de abertura merece particular destaque a discussão a respeito da crise e desarticulação das definições clássicas do humor, ancoradas na procura da essência do risível, e as análises, produzidas justamente no período estudado, das reflexões de Bergson, Freud e Pirandello que, a partir de perspectivas diferentes, enfatizaram o caráter histórico do humor e do cômico. 
Elias Saliba bem assinala o lugar central então ocupado pelas narrativas sobre a nação, temática que já possuía considerável tradição, mas que se revestiu de novos significados e conteúdos na passagem do século XIX para o XX. As representações humorísticas, assinala o historiador, desempenharam papel de relevo no processo de invenção das imaginações nacionais, e se fomentaram estereótipos, também contribuíram para modificá-los e desmistificá-los. Nessa perspectiva, cabe questionar: $\mathrm{O}$ que significaria, então, ser brasileiro num momento de aceleradas mudanças, marcado pela Abolição, República e pelo irromper dos substratos materiais da modernidade? Já éramos uma nação? $\mathrm{O}$ que nos faltava para atingir a completude ou, num tom mais pessimista, seria possível realizar tal proeza algum dia? Dilemas que também foram enfrentados pelos humoristas, como demonstra a primorosa pesquisa realizada.

Explicitados os fundamentos e objetivos da obra, o capítulo 1, Preparando o espírito para a Belle Époque, fornece ao leitor um rico panorama da produção humorística brasileira ao longo do século XIX, abarcando desde os folhetos cômicos do período regencial, pasquins, rodapés dos pequenos jornais até o surgimento das primeiras revistas ilustradas, que começaram a proliferar graças ao desenvolvimento da impressão e reprodução. A questão, porém, está longe de haver sido circunscrita aos seus aspectos técnicos. Como alerta o autor, nos decênios finais do Império,

(...) o recurso cômico era não apenas pouco difundido devido à inexistência dos próprios meios de difusão, mas também havia um mal disfarçado desprezo da cultura em geral pela produção humorística, a não ser quando esta se mostrava suscetível de ser incluída — ou classificada — nos moldes estéticos consagrados do romance, do drama ou da epopéia (p.43).

O que se admitia, no máximo, era o bom riso, que não destilasse rancor e tampouco atacasse frontalmente algo ou alguém em especial, postura exemplificada na maior parte da Enciclopédia do riso e da galhofa (1863), de um tal Pafúncio Semicúpio Pechincha, cognome Patusco Jubilado, pseudônimo adotado por Eduardo Laemmert. Quando não era esse o caso, e a narrativa continha (ou era lida como se contivesse) lances forte, com conotação degradante, obscena, grotesca ou marcada pelo rancor pessoal, rixas políticas, ressentimento social, a produção satírica acabava por ser cuidadosamente alocada nas margens da obra do escritor, como ocorreu com Bernardo de Guimarães e Olavo Bilac, por exemplo. Outros, que não adentraram o circuito da produção culta, acabaram esquecidos e proscritos do próprio mundo da escrita, caso de José Joaquim de Campos Leão, Hippolyto da Silva e Pedro Antonio Gomes Júnior.

Se a representação cômica da vida nacional não se iniciou na República, 
como o autor bem demonstra, parece assente que foi a partir dessa época que ela se intensificou e ganhou novas dimensões. No segundo capítulo, relativo à cidade do Rio de Janeiro, Saliba explicita quem eram os humoristas, sob que circunstâncias atuavam, de que forma se inseriam no campo intelectual, a auto-imagem que cultivavam. Num primeiro momento, a desilusão com o regime republicano congregou homens como Pardal Mallet, Lúcio de Mendonça, Paula Nei, Arthur Azevedo e José do Patrocínio que expunham, valendo-se das armas do humor, as contradições e paradoxos do regime recém instalado.

A esse grupo sucedeu outro, formado por Bastos Tigre, Emílio de Menezes, José do Patrocínio Filho, Raul Pederneiras, K. Lixto, J. Carlos, Storni, Yantok, que seguiu na trilha das críticas ao regime. É interessante notar que essa geração encontrava-se comprimida entre a alta cultura, representada, sobretudo, pelos parnasianos e simbolistas, e a atuação numa miríade de atividades que incluía artigos para jornais e revista, confecção de textos e desenhos para a nascente indústria do reclame, legendas e cartazes para filmes mudos, produção para teatro de revista, seja escrevendo roteiros, criando cenários e/ou figurinos, o que os obrigava a interagir com músicos, cantores, dançarinos, atores, diretores, encenadores, cenógrafos, enfim, todos os envolvidos nesse gênero misto destinado a atingir um público diversificado. As agruras que enfrentavam, a posição subalterna diante das fórmulas consagradas, que os instava a elaborar paródias e anúncios de acordo com os postulados da boa métrica, mas também a premência de agradar o público, atender às demandas dos meios de comunicação modernos e do mercado de bens culturais, que exigiam rapidez, concisão e versatilidade, os aproximava da oralidade, da fala coloquial, tornando-os uma espécie de ponte entre dois mundos. Além de explorar, com riqueza de detalhes, os aspectos mencionados, Saliba não deixa de perguntar como essa produção foi recebida pela elite letrada e de apontar a força do estigma por ela instituído, capaz de constranger esses homens, sintomaticamente denominados de ratés, a admitirem, implícita ou explicitamente, que não faziam literatura.

Questões de natureza semelhante são desenvolvidas no capítulo 3, consagrado aos humoristas radicados em São Paulo que, de forma ainda mais contundente, foram varridos da memória da cidade, possivelmente em função do conteúdo antiprogramático da sua produção, além de não se poder desprezar o fato de eles terem ficado ao largo do movimento de 1922. Os nomes de maior destaque foram: José Agudo (José da Costa Sampaio), Voltolino (Lemmo Lemmi), Cornélio Pires, Raul de Freitas, Juó Bananéri (Alexandre Ribeiro Marcondes Machado), Oduvaldo Vianna, Victor Caruso, Belmonte (Benedito Carneiro Bastos Barreto), Moacyr Piza, Hilário Tácito (José Maria de Toledo Malta) e, assim como ocorreu com os humoristas radicados na capital federal, muitos 
deles também transitaram por diferentes práticas culturais, ainda que as oportunidades oferecidas em São Paulo fossem bem mais restritas.

Saliba nos conduz à alta sociedade paulistana da Belle Époque por meio dos romances de José Agudo, ao universo caipira com Cornélio Pires, à babel moderna com o falar macarrônico, que atingiu seu melhor estilo em Juó Bananéri. Consegue, desta forma, dotar de materialidade a ebulição que caracterizava a cidade, com suas levas de desenraizados: ex-escravos, caipiras, imigrantes de origens variadas, que tanto preocupavam os detentores do poder e da ordem. A irreverência, porém, lhes custaria caro, pois:

(...) parece claro, afinal, que Bananéri e seus confrades, com seu hibridismo sintático, sua mestiçagem idiomática e seu anarquismo macarrônico, tinham se tornado um pouco inconvenientes naquela fábrica de certezas que era o clima mental vigente na São Paulo dos anos 20 (p. 212).

As polêmicas nas quais se envolveram Alexandre Marcondes, sempre protagonizadas pelo personagem que criou, e vários de seus confrades humoristas, foram objeto de detida análise, descortinando perspectivas instigantes para compreender as linhas de força que estruturavam o campo intelectual do período, atravessado por antagonismos, adesões, fidelidades, amizades e de546 safetos.

Por fim, no capítulo 4, questiona-se a respeito das relações que se estabeleceram entre o humor típico da Belle Époque e as novas mídias que se tornavam realidade a partir dos anos 30: o disco, o cinema sonoro, o rádio. $\mathrm{O}$ autor demonstra, de forma inequívoca, que os humoristas não tiveram dificuldades em se adaptar aos meios que então surgiam, graças à experiência que haviam acumulado:

(...) a mistura lingüística, a incorporação anárquica de ditos e refrões conhecidos por ampla maioria da população, a concisão, a rapidez, a habilidade dos trocadilhos e jogos de palavras, a facilidade na criação de versos prontamente adaptáveis à música, aos ritmos rápidos da dança e aos anúncios publicitários (p. 228).

As oportunidades abertas pela indústria fonográfica são exemplificadas com Cornélio Pires, pioneiro que, em 1929, já ostentava uma série inteira gravada com suas anedotas e crônicas, baseada na fala caipira, e Juó Bananére, que não chegou ao rádio em função de sua morte precoce. Saliba envereda, ainda, pelas relações entre humorismo e música, reconstruindo especialmente os diálogos entre Lamartine Babo e Bastos Tigre:

(...) espécie de último elo nessa tendência de intermediação cultural que praticamente constituirá a base para o humor radiofônico nos anos 30 e 40, com a 
geração do Capitão Furtado, Nho Totico (Vital Fernandes da Silva), Adoniram Barbosa, Ademar Casé, Renato Murce, Lauro Borges, Castro Barbosa, Gino Cortapassi e tantos outros(p. 283).

Ao lado da cuidadosa pesquisa, rigor e perspicácia analítica, na melhor tradição dos estudos culturais, Raízes do Riso distingue-se pela riqueza do material iconográfico, apuro editorial e estilo elegante do autor, que não se furta a brindar o leitor com excelentes tiradas de humor, fazendo jus a uma de suas epígrafes: "O humor não é um estado de espírito, mas uma visão de mundo" (p. 15).

Resenha recebida em 09/2002. Aprovada em 10/2002. 